\title{
Significant Points in Complicated Appendicitis
}

\author{
Erdinç Kamer $^{1} \cdot$ Serkan Karaisli ${ }^{1}$
}

Received: 3 June 2017 / Accepted: 11 August 2017 / Published online: 17 August 2017

(C) Association of Surgeons of India 2017

\section{Dear Editor,}

We read with keen interest the article titled "Is Interval Appendectomy Necessary for Appendicular Phlegmon? A Prospective Study" by Motie et al. published in 2017 issue of the Indian Journal of Surgery [1].

Acute appendicitis (AA) is one of the most common surgical emergency worldwide (7-8\%) [2]. Standard treatment of AA is appendectomy [2]. However, in recent years, publications have reported that antibiotherapy may be used in uncomplicated appendicitis [2]. However, no consensus was achieved in the treatment guidelines regarding the approach to complicated appendicitis [3]. In a study of Miftaroski et al., interval appendectomy was recommended after antibiotic treatment in the case of $<3-\mathrm{cm}$ abscess or phlegmonous appendicitis [3].

Motie et al. divided patients into three groups as A, B, and $\mathrm{C}$ in their study. Group A consisted of the patients that were followed up for a month after discharge from the hospital. In this group, it is understood that only conservative treatment was applied for the patients. Authors should clarify that point. The remaining patients were randomly divided into groups B and C. For readers, it is important that the authors specify randomization methods. In addition, patients in a group underwent interval appendectomy while the patients in another group were treated only conservatively. Patients in group C constitute a very risky group for a prospective study. We won- der what kind of explanation was made to the patients in group $\mathrm{C}$ about the study. Also, it was not mentioned which method for interval appendectomy was performed (open or laparoscopic). The authors followed up the patients after discharge in group $\mathrm{A}$ and $\mathrm{C}$ during 1 month and 6 months, respectively. We believe that it will be worthwhile to share their thoughts about the criteria they used to designate these follow-up times and why they did not insert group A to randomization.

\section{Compliance with Ethical Standards}

Conflict of Interest The authors declare that they have no conflict of interest.

\section{References}

1. Motie MR, Ahmadabadi A, Vejdani M et al (2017) Is interval appendectomy necessary for appendicular phlegmon? A prospective study. Indian J Surg. doi:10.1007/s12262-017-1644-9

2. Miftaroski A, Kessler U, Monnard E, Egger B (2017) Two-step procedure for complicated appendicitis with perityphlitic abscess formation. Swiss Med Wkly 147:w14422

3. Sun F, Wang H, Zhang F, Zhang X, Xing Z, Zhang S, Zhang H, Wang Y (2017) Copious irrigation versus suction alone during laparoscopic appendectomy for complicated appendicitis in adults. J Investig Surg 9:1-5
Serkan Karaisli

skaraisli@hotmail.com

Erdinç Kamer

erdinc.kamer@gmail.com

1 General Surgery Department, Izmir Katip Celebi University Ataturk Training and Research Hospital, Izmir, Turkey 